\title{
Desafíos na formación de comunicadores para a era dixital. Panorama diante da aplicación do documento de Bolonia: viaxe de Santiago ás capitais da Unión Europea
}

Xosé López*

A formación dos comunicadores no noso espacio de referencia, o espacio europeo, presenta unha gran variedade de modelos, con diferencias importantes entre os países do norte e do sur. A experiencia acumulada durante o século XX permítenos disponer dun referente nesta hora de reflexión, a que marca o calendario europeo da man do documento de Bolonia. Nunha ollada ó futuro, convén aproveita-los pasos adiante que ofreceron resultados positivos e corrixir aqueles aspectos que non funcionaron.

O paso do tempo deixou atrás moitas resistencias á formación universitaria dos comunicadores, que hoxe compartese desde moi diferentes frontes, aínda que segue despertando algunhas críticas. Hai, pois, un panorama marcado por dúas posturas claramente diferenciadas, das que eu defenderei desde o primeiro momento o criterio maioritario, o que sostén que os mediadores profesionais da Sociedade da Información, unha sociedade cada vez máis complexa, precisan unha boa formacióna que, neste momento, ten que ofrece-la a Universidade.

A formación dos comunicadores convén que esté nas mans da Universidade, a que temos que esixirlle unha resposta que combine os activos da Academia, da mellor tradición académica das Humanidades e as Ciencias Sociais, coas características da actividade profesional, os novos perfís e uns coñecementos actuais que preparen ós profesionais para a era dixital. A día de hoxe disponemos de bastantes exemplos que, con esta formulación, se crearon e consolidaron nos últimos anos en distintas universidades europeas.

\section{0 proxecto de Santiago}

Para analizar algunha destas experiencias que se levaron adiante na Universidade española, elixirei o caso de Santiago, que naceu en 1991, vinte anos despois de que

* Jornalista, professor da Universidade e, na actualidade, decano da Faculdade de Ciências da Comunicação de Santiago de Compostela. Texto da conferência na sessão de abertura do I Encontro Nacional sobre o Ensino de Jornalismo em Portugal, realizado na Universidade do Minho, em Braga, em 17 e 18 de Setembro de 2003. 
chegaran os estudios de Xornalismo á Universidade e nun momento de revisión crítica dos programas que marcaron esa primeira etapa. O proxecto de Compostela, levado adiante por profesores da Universidade Autonoma de Barcelona, combinou formación teórica con práctiva, definiu o campo das áreas de coñecemento de Comunicación e fuxiu da masificación.

Once anos despois, hai unha valoración positiva do camiño recorrido, pero o proxecto de actualización segue aplicándose para estar ó día. O obxectivo de mellorala formación dos xornalistas en Galicia esixe aínda hoxe unha actualización dos programas de estudio da Facultade de Ciencias da Comunicación que respondan as demandas da sociedade, a potenciación das liñas de investigación que contribúan a un mellor coñecemento do mundo da comunicación onte e hoxe, a organización de actividades de formación continua e un proxecto de calidade que asegure o cumprimento destes plans. As actuacións concretas que apuntei hai que acompaña-las en todo momento cunha reflexión xeral, con participación do maior número de actores, sobre os acertos e fallos do modelos vixentes nos principais países do noso entorno e, en xeral, dos países máis innovadores nesta materia no escenario mundial.

A existencia dun proxecto de Facultade de Ciencias da Comunicación na Universidade de Santiago que mereceu unha avaliación positiva dos expertos das universidades españolas mostra o acerto no seu deseño, pero entendemos desde o primeiro momento que non debía ser motivo para evitar lo debate sobre pasos adiante que deben darse para un mellor cumprimento dos seus fins. Tanto o proxecto inicial, respaldado por un grupo de catedráticos das principais universidades do Estado español, como a avaliación da súa titulación de xornalismo, a única que impartiu ata o curso pasado e que agora se completará con Comunicación Audiovisual desde o curso 2003-2004, completaron a fase de asentamento do centro, que agora avanza cara unha maior calidade no ensino que ofrece.

$\mathrm{O}$ informe da comisión externa de avaliación ${ }^{1}$ e o informe final sentaron as bases para o desenvolvemento do proxecto de facultade no primeiro tercio do século XXI. Despois dos primeiros pasos, nos que houbo que vence-los problemas derivados da escasez de medios e da ausencia de experiencias nalgúns campos ${ }^{2}$, tódolos datos apuntan que hai froitos positivos. Os equipos de investigación dan a coñece-los estudios sobre distintos aspectos do hipersector en Galicia e a súa participación no encontros nacionais e internacionais resulta especialmente significativa.

Aínda que non se cumpriron tódolos obxectivos fixados, percibo unha sensación interna e externa favorable á marcha do centro. Non digo que non haxa críticas, que as hai e sempre resultan positivas, pero afirmo que tódolos integrantes - alumnos, personal de administración e servicios e profesores - entenden que se andivo a etapa máis difícil. Agora, na fase de mellora, contamos con moitos máis referentes para

\footnotetext{
${ }^{1}$ A comisión de avaliación externa, presidida pola catedrática Rosa Franquet, destacou o enorme potencial do centro. No estudio de fortalezas e debilidades, faise referencia á boa planificación de medios para acometer unha formación de xornalistas na sociedade actual.

${ }^{2}$ A Facultade de Ciencias da Comunicación de Santiago foi a primeira do Estado en deseñar e aplicar un programa de formación por cuadrimestres.
} 
arroupar un proxecto que é de todos e que necesita do maior número de aportacións deseinteresadas para que o país dispoña dun centro de formación de comunicadores que contribúa ó cambio que se precisa no hipersector.

\section{Máis complexidade}

Moi poucos dubidan que a sociedade é cada vez máis complexa e, polo tanto, a interpretación do que nela acontece entraña novas dificultades. O escenario actual, o que convimos en chamar da Sociedade da Información e o Coñecemento, ten a comunicación como aspecto central e, polo tanto, a formación dos profesionais que traballan neste hipersector ten que ofrecer respostas ós desafíos actuais. E son as Facultades de Ciencias da Comunicación, a partir da experiencia de máis de trinta anos, as que deben aportar propostas concretas para a innovación e a mellora dos plans de estudio.

Os profesionais do xornalismo, mediadores, intérpretes e xestores do coñecemento, precisan unha boa formación para o exercicio profesional na era dixital - é o contorno tecnolóxico que marca o traballo e do coñecemento das ferramentas vellas e novas que resulten eficaces para a divulgación do coñecemento. Os aspectos centrais das ciencias sociais e das humanidades, xunto coas cuestións específicas da comunicación, constitúen pilares básicos na preparación deses comunicadores da era dixital, que teñen que disponer cando se licencian duns coñecementos básicos para seguir ampliando a súa formación.

A experiencia destes anos - a segunda metade do século XX - demostrou que o profesional dos medios de comunicación, que durante moitos anos aprendeu o oficio na redacción, necesitaba unha inmersión no mundo universitario para, da man dunha titulación superior en Comunicación, coñece-lo funcionamento da sociedade, as ferramentas de análise para entende-lo entramado económico, social e político, as técnicas da elaboración das mensaxes para os distintos soportes, e o exercicio práctico que revalida a súa capacitación para incorporarse á sociedade para atende-las demandas sociais e do mercado.

Os avances na formación dos xornalistas no século XX foron moi significativos en España. A discusión sobre a necesidade e natureza dun sistema de formación profesional e/ou académica para o exercicio do xornalismo mantívose durante as primeiras décadas do século XX estreitamente vinculada a cuestión da liberdade de prensa (María Luisa Humanes, 1997: 159) ${ }^{3}$. Desde os primeiros anos do franquismo houbo especial interese por deseñar modelos de formación e control dos xornalistas. E xa nese momento houbo propostas para leva-los estudios á Universidade, ben como unha sección de periodismo nas facultades de letras ou mediante a creación de catro facultades (Enrique Aguinaga, 1984: 140)4 . O final non foi ata 1971 cando os estudios de xornalismo

\footnotetext{
${ }^{3}$ A profesora María Luisa Humanes analizou esta cuestión na súa tese de doutoramento. Nesta investigación analiza o papel da escuela de El Debate como referente.

${ }^{4} \mathrm{O}$ mestre Enrique de Aguinaga explica, na súa tese de doutoramento, o proxecto de lei de Prensa de Jiménez Arnau que contemplaba a creación de catro facultades.
} 
chegaron á Universidade, logo de vence-la resistencia dalgúns sectores do réxime franquista (María Luisa Humanes, 2002: 625) 5 . Foi o primeiro paso dun proxecto que se axustou a nova realidade democrática e chegou ata hoxe.

\section{0 que facemos}

Logo da aparición das primeiras facultades en Madrid, Barcelona e Navarra, no ano 1971, nas últimas décadas do século XX apareceron novos centros. E nesta fase, a comezos da década dos noventa, cando Santiago pon en marcha a súa Facultade de Ciencias da Comunicación coa titulación de xornalismo. Era un paso decisivo para a comunicación e para a construcción do país galego. Foi o punto de partida do actual proxecto.

Desde o seu nacemento, a Facultade de Ciencias da Comunicación de Santiago de Compostela forma xornalistas preparados coa necesaria dimensión teórica e técnica dos estudios de comunicación... A experiencia e coñecemento dos modelos internacionais que existen na Europa comunitaria e nos países do norte de América permitiu definir un modelo de éxito, que deseñou unha comisión de expertos coordinados polos profesores Margarita Ledo e Emilio Prado. Os resultados destes anos mostran o acerto da liña seguida polo centro de formación de comunicadores da Universidade de Santiago, que traballa na actualización dos programas docentes e das técnicas de ensino.

Desde o primeiro momento, o centro de formación de comunicadores en Galicia concebiuse de xeito que fose capaz de garanti-la formación de profesionais, potencia-la investigación e a reflexión sobre os problemas da comunicación e da cultura. Tamén se prestou atención os programas dirixidos á formación continua dos profesionais do sector, que se teñen que adaptar ás esixencias dun mundo en permanente evolución. Segundo o documento fundacional das liñas mestras do proxecto de plano de estudios da Facultade, concebiuse a teoría como un conxunto de principios verificables, tamén, nunha "escritura", nunha "realización" informativa e comunicativa, e non somente nunha "lectura".

\section{Teoría e producción}

Nunha concepción moi actual, deféndese que a función da teoría non debe limitarse a reflexionar sobre da problemática da significación destiñada a producir un coñecemento capaz de xerar unha competencia de "lectura". Preténdese que cumpra tamén, sen excusa, a función de xerar unha competencia operativa destinada á producción das mensaxes nos eidos de comunicación.

O que se busca, desde a creación da Facultade, é producir un saber que permita coñece-los mecanismos, convencións e lóxicas culturais e sociais que posibilitan o complexo proceso de producción de sentido e ó mesmo tempo posibilite un percorrido

\footnotetext{
${ }^{5}$ O xornalista Emilio Romero apoiou esta iniciativa e fixo todo o posible para convencer a algúns procuradores, segundo explica nas súas memorias e segundo recolle María Luisa Humanes en varios dos seus traballos.
} 
inverso interpretando o que propón o discurso. Inténtase, en definitiva, que a teoría sirva para caracteriza-la técnica e que haxa unha interacción entre ámbalas dúas.

O principal obxectivo, é, con estas formulacións contextuais básicas, preparar comunicadores con sentido expresivo na escrita e no audiovisual, que dominen as técnicas de expresión oral e visual, ademais da redacción, adaptada ás esixencias derivadas das características peculiares de cada medio. Os profesionais deben coñece-las tecnoloxías actuais para efectuar esa expresión tirándolle o máximo rendemento na producción informativa e comunicativa.

\section{Respostarlle ó mercado}

Da man destas liñas de actuación, o que se trata no traballo diario é de suministrarlle ó alumno "saber" e "saber facer". Así trátase de respostar con eficacia ás necesidades do mercado da comunicación e da información e ás demandas sociais, no marco das directrices emanadas do Consello de Universidades, esixencia imprescindible para o recoñecemento oficial do título.

No momento actual, cun plano de estudios actualizado e aplicado desde o curso 1999-2000, impártense dous itinerarios, un de periodismo audiovisual e outro de periodismo electrónico e multimedia. No futuro poñerase en marcha o terceiro itinerario, o de fotoperiodismo e imaxen documental, que se completará coa titulación de Comunicación Audiovisual, cun itinerario de Dirección e guión cinematográfico e audiovisual. Trátase dunha oferta axeitada as actuais posibilidades que ofrece a vixente normativa para o ensino superior.

O modelo de Santiago, que busca un equilibrio entre teoría e práctica aceptable, pode levarse adiante gracias as instalacións do moderno edificio de Álvaro Siza, unha xoia arquitectónica que actúa como referente no conxunto das facultades de Ciencias da Comunicación do Estado. Os modernos equipos de televisión, radio e informática permiten o desenvolvemento de programas prácticos axustados os sistemas de producción que se aplican nos principais medios de comunicación.

\section{Defini-los novos camiños}

Mentres se produce esta resposta ós novos desafíos, o centro segue funcionando e a reflexión sobre os camiños a seguir chegan desde distintos frontes. A propia investigación universitaria favorece esta vía ${ }^{6}$ que debe ofrecer ideas para defini-los novos camiños a partir da experiencia destes anos. Hai documentos para un novo marco, nomeadamente o coñecido como Documento de Bolonia sobre o espacio europeo do ensino superior, que obrigarán a dar novas respostas os desafíos que temos diante. Trátase de marcos que guiarán o que debe se-lo obxectivo prioritario das Facultades de Ciencias da Comunicación: formar ben os xornalistas para a era dixital.

\footnotetext{
${ }^{6}$ Unha das últimas teses de doutoramento sobre esta cuestión presentouna con éxito na Facultade de Ciencias da Información de Madrid o xornalista galego Xosé Videla, quen fai prospectiva sobre camiños a seguir.
} 
Eses xornalistas do actual século precisan coñecer non só as claves do xornalismo herdado, senón das innovacións xornalísticas destes novos tempos. Somos conscientes de que o desenvolvemento da industria de contidos puxo sobre a mesa o déficit da oferta de persoal nalgunhas áreas, tendencia que previsiblemente se manterá a curto e longo prazo. Existe unha coincidencia maioritaria no sector. É por iso que os centros de formación de xornalistas, sen esquece-lo seu principal obxectivo - a boa formación xornalística, cunha preparación universitaria - deberán crear renovados itinerarios que atendan os perfís nos que existe maior demanda e os que resultan fundamentais para unha sociedade ben informada.

As esixencias de adaptación os tempos actuais están ahí e as facultades - en concreto, a Facultade de Ciencias da Comunicación de Santiago - están dando respostas que considero acertadas e imaxinativas. Sei que non hai respostas perfectas - case sempre hai posibilidades de melloralas, enriquece-los programas -, pero temos que tentar anticiparnos ó futuro cun bo coñecemento das necesidades e tendencias do presente. Esa é a aposta do centro de Santiago neste comezo de século.

\section{Primeiros pasos}

Ata aquí puxemos como exemplo a Facultade de Ciencias da Comunicación de Santiago na medida en que podo falar dela con datos de primeira man, xa que coñezo bastante ben o seu nacemento e evolución, pero sobre todo porque pertence a un grupo de centros que aproveitou a experiencia dos primeiros anos da formación universitaria dos comunidadores en España e que tentou corrixir algúns erros. Falamos, pois, dun modelo de referencia sometido a análise e revisión neste momento.

Este modelo de referencia convive con outros non menos importantes. Convén recordar que en España hai tres grandes grupos de facultades: as nacidas no ano 1971 (como xa dixemos, as principais, que son a Complutense de Madrid, Autónoma de Barcelona e Universidade de Navarra), as nacidas xa medidados da década dos oitenta e noventa, e as nacidas no terceiro milenio. A de Santiago, como dixemos, pertence o segundo grupo, no que están outros centros importantes como os de Bilbao, Sevilla ou Málaga.

Sen dúbida, nestes anos, os principais focos de investigación e docencia estiveron en Madrid, Barcelona e Navarra, o que indica que tamén son estas facultades as que realizarán una maior aportación ó novo modelo de ensino superior de comunicación, que agora se trata de articular tendo como referencia o proceso de construcción do Espacio europeo de Educación Superior, iniciado coa Declaración da Sorbona de 1998 e consolidado coa Declaración de Bolonia de $1999^{7}$.

\footnotetext{
${ }^{7}$ A Declaración de Bolonia insta ós Estados membros da Unión Europea a adoptar un sistema de titulacións comprensible e comparable que promova oportunidades de traballo para os nosos estudiantes e unha maior competitividade internacional do sistema educativo europeo. Este novo sistema debe basarse en dous niveis, un primeiro de Grado que capacita ós estudiantes a integrarse directamente no mercado de traballo europeo cunha cualificación profesional apropiada, e un segundo nivel de posgrado que se estructura nos ciclos de Master e Doctorado.
} 
Neste marco xeral europeo, que busca uns títulos de comunicación que sexan homologables tanto no primeiro nivel, no de Grado, como no segundo, de Posgrado, con ciclos de Máster e Doctorado, as autoridades españolas veñen de aprobar unha Lei, a Lei Orgánica 6/2001 de Universidades, que xa reclama a integración do sistema universitario español no novo espacio universitario europeo. A citada Lei autoriza ó Goberno para proceder á reforma e adaptación das modalidades cíclicas das ensinanzas e os correspondentes títulos.

Para desenvolver esta Lei, o Goberno ten previsto un borrador de Real Decreto no que se establecerá a estructura do encino universitario e a regulación dos estudios universitarios oficiais de grado. Neste texto indícase que, con carácter xeral, o número de créditos totais de ensinanzas conducentes á obtención dos títulos oficiais de licenciado, enxeñeiro ou arquitecto será de 180 ou de 240 . O Goberno español tamén ten os proxectos de real decreto polo que se regulan os estudios universitarios de posgrado e a obtrención e expedición de títulos oficiais de master e doctor; o borrador polo que se establece o sistema europeo de créditos e o sistema de calificacións nas titulacións universitarias de carácter oficial e a validez en todo o territorio nacional; o borrador de real decreto polo que se establece o procedemento para a expedición polas universitades do suplemento europeo ó título; o borrador do proxecto de real decreto sobre homologación dos plans de estudios e títulos de carácter oficial e validez en todo o territorio nacional, e o borrador do proxecto de real decreto polo que se eregulan as condicións de homologación e convalidación de títulos e estudios extranxeiros de educación superior.

Diante deste panorama, os primeiros pasos dirixíronse a formaliza-la Conferencia de Decanos das Facultades de Ciencias da Comunicación, que os días 19 e 20 de xuño desde ano 2003 se reuniron en Barcelona para aproba-lo seu regulamento de fruncionamento e completa-la estructura organizativa. Nese encontro, decidiuse concurrir á convocatoria de axudas para o deseño de plans de estudio e títulos de grado, convocado pola Agencia Nacional de Evaluación de la Calidad y Acreditación (ANECA) nun intento de unificar posturas entre os centros e deseñar un modelo de plans de estudio e títulos de grado que teña en conta a experiencia destes anos e sexa homologable en Europa.

\section{Qué camiño seguir?}

Na percura dun modelo de plan de estudio que esté integrado no espacio universitario europeo, as facultades españolas parten con varios condicionantes, entre os que destacaremos os cinco anos que agora teñen os estudios de grado nalgúns centros - na Universidade Complutense, nas privadas...; diversidade de carga práctica nos planos de estudios; peso dos departamentos doutras titulacións nos estudios de comunicación.... O punto de partida non é o mesmo, polo que entraña certa dificultade o deseño dun proxecto que desperte unanimidades.

Con todo, hai vontade de buscar un acordo de liñas xerais que inclúe unha duración dos estudios de catro anos - hai centros importantes que non asumen comezar agora, nesta fase, con tres anos para o título de grado -, mantemento das titulacións de 
Xornalismo, Publicidade e Relacións Públicas e Comunicación Audiovisual, un mínimo de troncalidade común que non sexa inferior o 50/60 por cento das materias - o Goberno prevé troncalidade común do 70 por cento -, Masters moi especializados, con itinerarios de un ou dous anos que teñan en conta as demandas do mercado, doutoramentos que fomenten a preparación de bos investigadores....

Non será fácil, pero hai vontade de afronta-lo desafío. O camiño a seguir é partir do que nos une para buscar un proxecto que permita un paso adiante, un paso de tránsito, que facilite, nunha segunda fase, poñer títulos de grado de tres anos. Entendo que se este é un dos puntos sobre os que a medio prazo haberá que reflexionar entre o maior número de facultades dos principais países da Unión Europea, sobre todo se queremos unha solución que teña en conta a necesidade dunha boa preparación e a maior unificación de criterios no referido os programas xerais dos títulos de grado.

En canto a investigación, precisamos establecer un modelo que garantice unha boa prepración dos investigadores, con programas intensos e que superen periódicamente controles de calidade. A Unviersidade non está no campo da formación profesional, senón que precisa fomenta-la investigación e garantir que no campo das Ciencias da Comunicación se avance con firmeza. Cumprir tal obxectivo só será posible no caso de que se establezan programas que favorezan a formación nos propios centros, faciliten a mobilidade/intercambio no conxunto de Europa e América, e fomenten o avance científico.

\section{Polos vieiros da calidade}

No escenario actual, de novos desafíos, os camiños a seguir teñen un horizonte moi definido: mellora-la calidade. O modelo actual ten aspectos básicos que mostraron, nestes anos, que supuxeron pasos adiante. Refírome a unha boa combinación entre teoría e práctica - un equilibrio na formación; unha preparación que teña en conta as demandas do mercado pero sen renunciar o que é básico na Universidade; unha formación teórica que garantice unha formación xeral do alumno que lle permita pensar por el mesmo; un bo aproveitamento da investigación propia e allea para mellora-la formación e o coñecemento científico...

A Universidade ten que seguir sendo Universidade no terceiro milenio. Cumprir este obxectivo non debe impedir atende-la demanda dos novos perfís que demanda o mercado, unha atención á herdanza no campo da Comunicación e os seus avances nestes anos, e respostas imaxinativas ós novos retos. Todo no marco do modelo europeo, que aparece como un requisito básico para intervir no novo escenario. Gaña-lo futuro quere dicir aproveitar axeitamente o que estamos facendo ben e corrixindo os erros naqueles ámbitos donde non conseguimos avanzar. O primeiro reto define en cada país e o segundo na colaboración entre os centros do maior número de países. Así daremos os primeiros pasos. Os seguintes xa esixirán unha integración mayoritariamente, nun modelo acordado segundo as directrices xerais de Bolonia. 


\section{Bibliografía}

Aguinaga, E. (1984). Epistemología de la Profesión Periodística: Los Estudios de Periodismo y su Proyección Profesional, Tesis doctoral, Madrid: Universidad Complutense: Madrid.

Humanes, M. L. (1997). La Formación de Periodistas en España, Tese Doctoral, Madrid: Universidade Complutense.

Humanes, M. L. (2002). 'La Política de Formación de Comunicadores: La Escuela Oficial de Periodismo (1941-1970)', in Galindo, G.; Lozano, G.; Alarcón, S. (eds.). La Comunicación Social durante el Franquismo, Málaga: Diputación Provincial de Málaga.

Videla, X. X. (2002). La Formación de los Periodistas en España: Perspectiva Histórica y Propuestas de Futuro, Tese de Doutoramento, Madrid: Universidad Complutense.

\section{Resumo}

O modelo de formación dos xornalistas en Galicia mediante un programa actual está nunha fase consolidación. Logo de dez anos, a Facultade de Ciencias da Comunicación deu mostras da súa capacidade para poñer en marcha modelo que responda as necesidades do país e que está inspirado nos plans de estudio máis dinámicos das universidades europeas e norteamericanas. No comezo do terceiro milenio, estase cun proxecto para promove-la formación continua dos comunicadores nun escenario dixital e para prepara-lo mellor posible ós futuros xornalistas. A adaptación ós novos tempos é un reto permanente.

Palabras clave: formación, xornalismo, ensinar xornalismo

\section{Abstract}

The model for journalism education in Galicia with an updated programme is consolidating. After ten years, the Faculty of Communication Sciences has been showing its capacity to develop a model which answers the needs of the country and that find inspiration in the more dynamic programmes of studies in the European and North American universities. In the beginning of the Third Millenium, we are working in a project to promote the continuous training of the journalists in the new digital scenery and also to assure the best education for the future professionals. The adaptation to the new times is a permanent challenge. 